\title{
Improved Power Production of Tidal Current Power by Reformed Turbine Configuration
}

\author{
Chul H. Jo, Doyoub Kim, Chan H. Goo \\ Inha University \\ 100 Inha-ro, Nam-gu, Incheon, South Korea \\ chjo@inha.ac.kr, doyoubkim815@inha.edu,gch99@inha.edu
}

\begin{abstract}
The importance of renewable energy has been increased with the worldwide effort to reduce the $\mathrm{CO}_{2}$ emission and more after the nuclear power station accident in Japan on March 11, 2011. Among various renewable energy sources, tidal current power is recognized as the most promising energy source with characteristics of predictability and reliability. Generally, tidal current turbine has two or three blades and being deformed in operation due to the continuous dynamic loadings caused by current and wave. The deformed rate of blades is dependent on flow velocity, blade size, and material property. From the deformed blades, the projected area becomes smaller than the intact condition which can lead to the decrease of power production. To understand the power decrease rate due to the deformed turbine, a fluid-structure interaction analysis was conducted using computational fluid dynamics (CFD) and the finite element method (FEM). The reformed blade configuration is suggested to improve and optimize the power production of tidal current converters.
\end{abstract}

Keywords: tidal current power, fluid-structure interaction, reformed blade, deformed blade, horizontal axis turbine

\section{Introduction}

Many studies have been performed on tidal turbine designs based on the blade element momentum theory (Batten et al. [1]). Bahaj et al. [2] conducted an experimental demonstration of tidal turbine performance. A study on the evaluation of the 3bladed horizontal axis tidal turbine performance considering measured vertical velocity profile at the Bristol Channel, England was conducted. Early tidal energy arrays are now in the planning and consenting stage but there are several important issues for commercial development such as performance under ocean environment, interactions between devices, etc. In the previous research a performance analysis for tidal turbines considering the effects of regular waves was introduced. For interference effect of multi-arrayed tidal turbines, diagonal arrangement has advantages that could mitigate interactions accelerating the flow between 2 upstream turbines (Jo et al. [3]). The wake characteristics behind a three-bladed turbine were introduced by analysing with unsteady CFD method to investigate the velocity recovery pattern (Jo et al. [4]). A numerical study on the turbine wake and optimal distance between turbines was presented as well by Harrison et al. [5]. However, there are few papers regarding to the performance changed due to the deformed blades which occurs in the ocean environmental conditions. The deformed blades surely affect to the turbine performance leading to the decreased power production rate. The study has investigate the effect of deformed blades to the power efficiency and suggested the reformed blade design to improve the power production.

\section{Blade Design and Deformation Analysis}

The basic blade design of S814 foil has been applied in this study. To develop the blade profile, the following equations are used. P in (1) represents the power capacity, which can be defined as the product of generated power from the turbine and the efficiency of power train $\eta$. In order to estimate the output of the turbine, the output coefficient $(\mathrm{CP})$, and the efficiency factors of the hydraulic power transmission gears and watertight device, are substituted into (1) as follows:

$$
P=\eta C_{P}\left(\frac{\rho \pi D^{2} U_{D}^{3}}{8}\right)
$$

Where the power train coefficient $(\eta)$ is generally determined to be 0.9 . Considering mechanical loss by friction in a watertight bearing, gearbox, etc., $\eta$ was conservatively assumed to be 0.85 in this research. 
The blades were designed based on the parameters shown in Table 1. To confirm the turbine design, three-dimensional (3-D) turbine modelling was performed using CATIA commercial software (version 5.19) as shown in Fig. 1.

Table 1: Design parameters of turbine.

\begin{tabular}{|c|c|c|}
\hline \multicolumn{2}{|c|}{ Design parameter } & Values \\
\hline$P$ & Rated power $(\mathrm{kW})$ & 200 \\
\hline$C_{p}$ & Power coefficient & 0.4 \\
\hline$U_{D}$ & Design current speed $(\mathrm{m} / \mathrm{s})$ & 2.5 \\
\hline$A$ & Tip speed ratio & 5 \\
\hline$A$ & Angle of attack $\left(^{\circ}\right)$ & 6 \\
\hline$D$ & Turbine diameter $(\mathrm{m})$ & 10 \\
\hline$N$ & Blade number $(\mathrm{EA})$ & 3 \\
\hline$\omega$ & Angular speed (rpm) & 23.87 \\
\hline
\end{tabular}

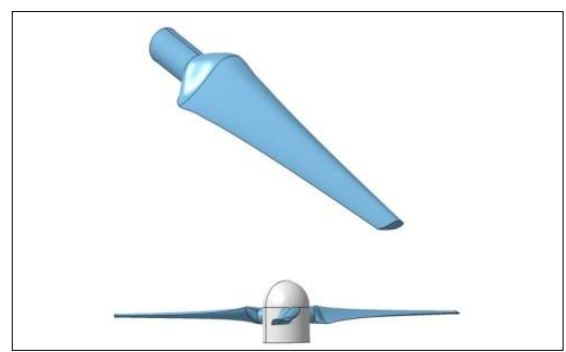

Fig. 1: Solid model of 3-D blade and turbine.

The numerical analysis based on 3-D Reynolds-averaged Navier-Stokes equations have been used for flow analysis together with CFD analysis to calculate the hydrodynamic loads on the blade. These results were then used in the FEM analysis as distributed external loads. An internal rotating domain encompassed the blade and the surfaces between two domains were interfaced using the general grid interface method. The computational domains were calculated by assuming that the flow between adjacent passages is periodic in the rotating direction. Grid generation was precisely conducted for smooth convergence and reliable results. A hybrid grid system was applied to the flow field, as shown in Fig. 2.

To estimate the turbine deformation, the fluid pressure load acting on the blade from CFD results was transported to FEM program. A composite material of E-glass fibre and epoxy was applied to the blade material property. Fig. 3 shows the deformed shapes of blades for various incoming current speed.

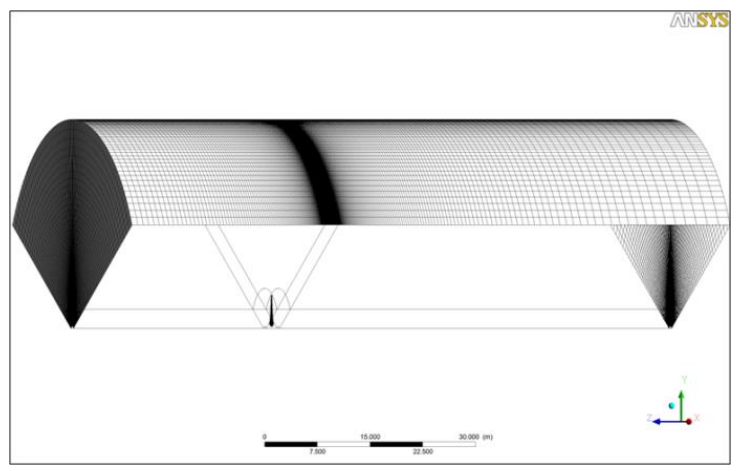

(a)

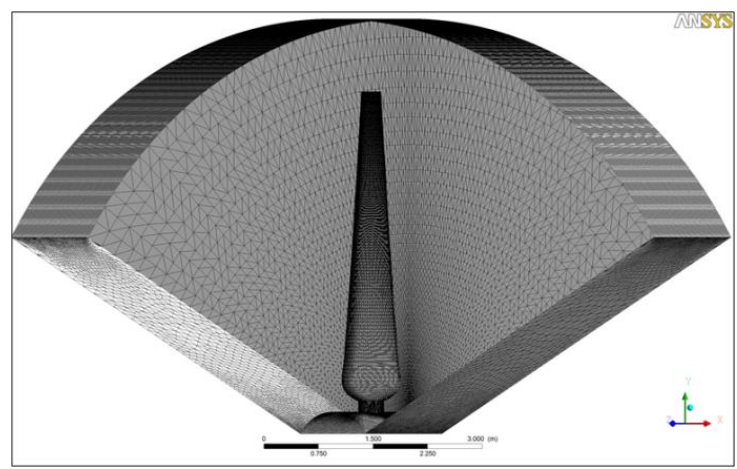

(b)

Fig. 2: (a) Computational domain with mesh, (b) Hybrid grid system in rotating domain. 


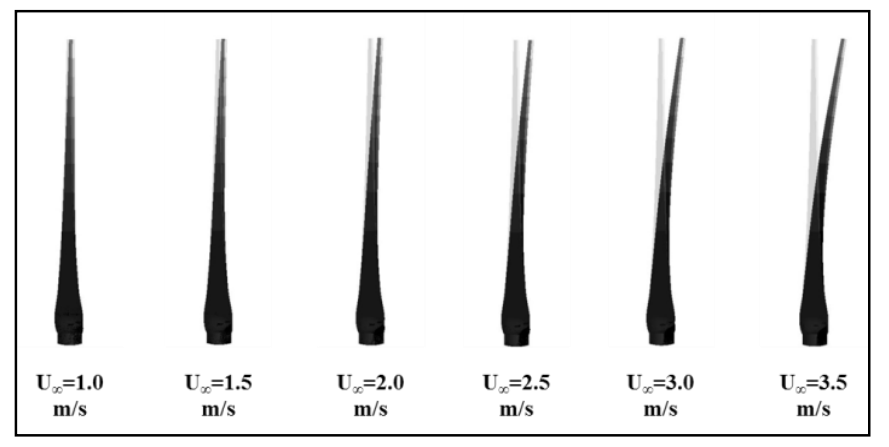

(a)

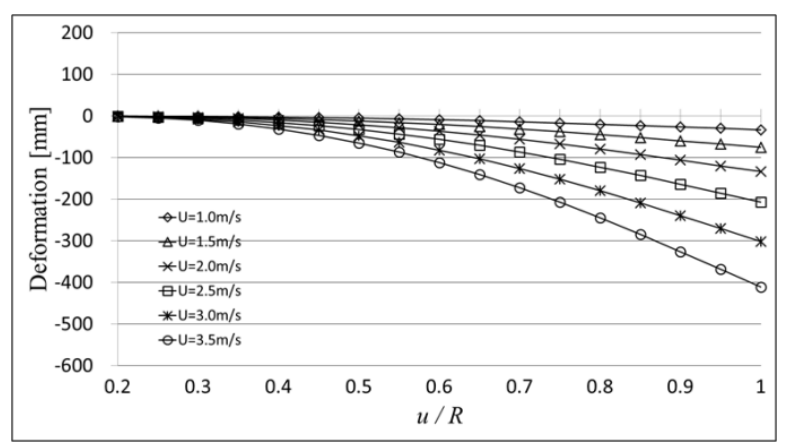

(b)

Fig.3: (a) Shapes of deformed blades, (b) Deformation along the blade span.

\section{Reformed Blade Performance}

The reformed turbine was designed to improve the power lost from the deformed blade. The reformed span coordinates and pitch angles at the design current speed of $2.5 \mathrm{~m} / \mathrm{s}$ for each span were transferred to a location diagonally opposite from the coordinates and pitch angles on the reference point of the rigid turbine. This blade is shaped to bend toward the current when the turbine blade is not subjected to hydrodynamic loads. Fig. 4 shows the designed reformed blades and their deflection at various current speeds.

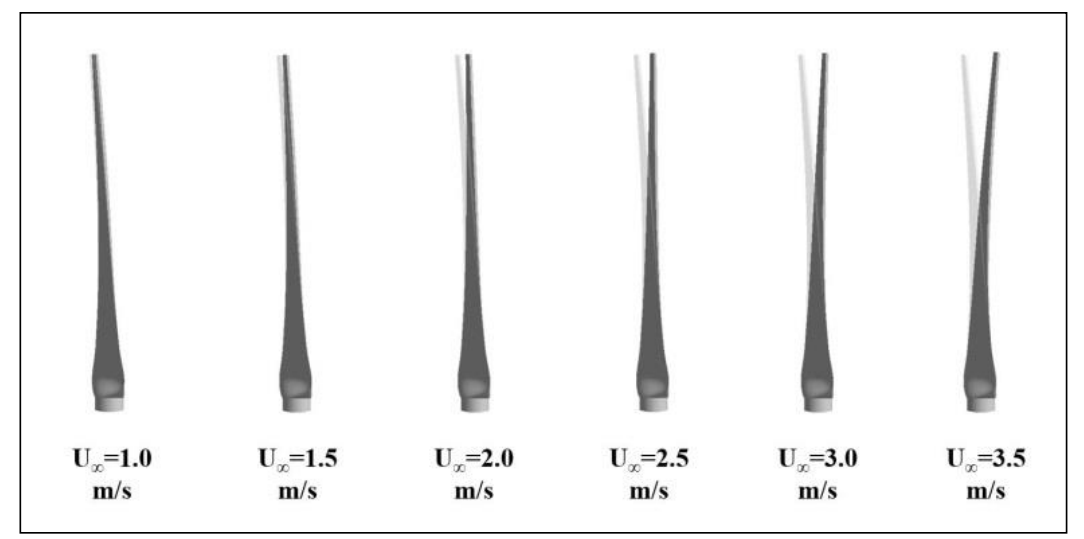

Fig. 4: Deflection of reformed blades.

The efficiency of reformed turbine shows a slightly lower than the rigid blade turbine this means that the reformed blade can compensate this loss. The rigid blade and reformed blade show a similar performance with respect to the maximum $C_{P}$ for various incoming velocities as shown in Table 2 .

Table 2: Turbine efficiency comparison.

\begin{tabular}{|c|c|c|c|}
\hline $\begin{array}{c}\text { Velocity } \\
(\mathrm{m} / \mathrm{s})\end{array}$ & $\begin{array}{c}\text { Efficiency of rigid } \\
\text { turbine }(\%)\end{array}$ & $\begin{array}{c}\text { Efficiency of deformed } \\
\text { turbine }(\%)\end{array}$ & $\begin{array}{c}\text { Efficiency of reformed } \\
\text { turbine }(\%)\end{array}$ \\
\hline 1.0 & 46.8 & 46.8 & 46.3 \\
\hline 1.5 & 47.3 & 47.1 & 47.0 \\
\hline 2.0 & 47.4 & 46.4 & 47.3 \\
\hline 2.5 & 47.6 & 45.6 & 47.5 \\
\hline 3.0 & 47.5 & 45.0 & 47.7 \\
\hline 3.5 & 47.6 & 44.9 & 47.9 \\
\hline
\end{tabular}




\section{Conclusion}

In this study, the tidal turbine deformation due to the hydrodynamic loading was verified by CFD and FEM methods and the power drops from the deformed turbine for various incoming velocity were estimated. To improve and increase the power production rate, the reformed blade concept has been proposed. The performance and the improved rate of reformed turbine over the ordinary rigid turbine can be analysed by Fluid Structure Interaction (FSI) technique. As an example, the efficiencies of a rigid and a deformed and a reformed blades at a design current speed of $2.5 \mathrm{~m} / \mathrm{s}$ were confirmed to be $47.6 \%$, $45.6 \%$, and $47.5 \%$, respectively. Approximately of $2 \%$ difference of efficiency can make a big difference in the annual power production rate that can be significant amount in the tidal farm project. Therefore, the reformed blade design could be an important issue in the tidal current power systems in order to mitigate the power loss caused by blade deformation. The application of reformed turbine could be an effective way to improve energy production over tidal arrays in the tidal farm facing with the power decrease by interaction problems.

\section{Acknowledgements}

This work was supported from the project titled 'Manpower training program for ocean energy', funded by the Ministry of Oceans and Fisheries, Korea and by KETEP project-201333030000260 and also the output of "Development of active controlled tidal stream generation system" funded by the Ministry of Oceans and Fisheries (20110171).

\section{References}

[1] W. M. J. Batten, A. S. Bahaj, A. F. Molland, and J. R. Chaplin, "Hydrodynamics of marine current turbines," Renewable Energy, vol. 2, pp. 249-256, 2006.

[2] A. S. Bahaj, W. M. J. Batten, and G. McCann, "Experimental verifications of numerical predictions for the hydrodynamic performance of horizontal axis marine current turbines," Renewable Energy, pp. 2479-2490, 2007.

[3] C. H. Jo, K. H. Lee, and J. Y. Yim, "A study on the interference effects for tidal current power rotors," International Journal Science China: Technological Sciences, 2010, vol. 11, pp. 3094-3101.

[4] C. H. Jo, J. H. Lee, Y. H. Rho, and K. H. Lee, "Performance analysis of a HAT tidal current turbine and wake flow characteristics," Renewable Energy, vol. 65, pp. 175-182, 2014.

[5] M. E. Harrison, W. M. J. Batten, L. E. Myers, and A. S. Bahaj, "A comparison between CFD simulations and experiments for predicting the far wake of horizontal axis tidal turbines," IET Renewable Power Generation, vol. 6, pp. 613-617, 2010. 